\title{
Drivers of Food Choice among Pastoral/Agro-Pastoral Community in Somali Regional State, Eastern Ethiopia
}

\author{
Berhe Gebremichael (1) ${ }^{1}$ and Abiyot Asfaw ${ }^{2}$ \\ ${ }^{1}$ School of Public Health, Haramaya University, P.O.Box: 235, Harar, Ethiopia \\ ${ }^{2}$ School of Nursing and Midwifery, Haramaya University, P.O.Box: 235, Harar, Ethiopia \\ Correspondence should be addressed to Berhe Gebremichael; berhegere09@gmail.com
}

Received 7 March 2019; Revised 12 July 2019; Accepted 3 August 2019; Published 30 October 2019

Academic Editor: Carol J. Burns

Copyright (C) 2019 Berhe Gebremichael and Abiyot Asfaw. This is an open access article distributed under the Creative Commons Attribution License, which permits unrestricted use, distribution, and reproduction in any medium, provided the original work is properly cited.

\begin{abstract}
Background. Although nutritional problems are among the Ethiopian government's priorities, the progress of nutritional indicators in the pastoral/agro-pastoral community is below the national figure. This could be because of poor food choice decisions, which remains poorly understood. Therefore, this study aimed to explore the drivers of food choice among the pastoral/agro-pastoral community of Somali Regional State, Eastern Ethiopia. Materials and Methods. A qualitative study was conducted among 16 Focused Group Discussions (FGDs) and six Key Informant Interviews (KIIs) from May 7 to 27, 2018. Participants were selected purposefully. Native speakers of Somali language, who had previous qualitative data collection experience, collected the data. The overall collected data were cleaned, coded, sorted, categorized, and analyzed line-by-line. Content analysis was used to drive the key themes and sub-themes. Results. The study found that the commonest food item usually consumed by the community was porridge ("Shurow"), which is made from wheat or corn flour. The porridge is sometimes mixed with milk or butter. Besides, they consume boiled bean, wheat or sorghum ("Garaw") that is mixed with oil or sugar. However, the consumption of fruits and vegetables was rare and seasonal. These all indicate that their feeding habit was monotonous with poor food choice decisions. The reported driving factors of food choice included drought, income, cost, availability and quality of foods, market access, familiarity with new foods, knowledge of nutritious foods, and health status of individuals. Conclusions. The food choice of the community was poor in the study area. Therefore, the health and agricultural sectors should work together to improve the feeding habits of this community by improving their knowledge and the availability of nutritious foods.
\end{abstract}

\section{Introduction}

Improving nutrition across the life course from conception through adulthood is essential for the well-being of families and communities, and for the successful economic and social advancement [1]. Under-nutrition contributes for nearly half of all the annual under-five children mortality. Globally, $22.9 \%$, $7.7 \%$, and $6.0 \%$ of under-five-year children were stunted, wasted and overweight in 2016, respectively. The prevalence of stunting was highest in Asia (56\%) and Africa (38\%) [1,2].

The burden of malnutrition is more devastating in the pastoral/agro-pastoral community because of many challenges, including climate variability and change [3]. Pastoralists are communities whose primary livelihood activity is livestock production and sales; whereas agro-pastoralists are those whose primary livelihood activity is crop production and sales, complemented with livestock production and sales [4]. In sub-Saharan Africa, these communities are facing substantial challenges: poverty rates are high throughout the region, and food security is poor [5]. This is the reason they have been marginalized from national economies and political systems [6].

One study shows that increased climate variability may increase severe child stunting by $62 \%$ in South Asia and $55 \%$ in East and Southern Africa by 2050 [7], although many other variables may affect under-nutrition too [8]. Another study revealed, increased rainfall variability will increase the prevalence of underweight children in the future, and many of these children will be in the rangelands [9].

As pastoralist areas are often marginalized from centers of power, their needs are not adequately addressed in national planning processes. This is changing slowly, with decentralization of climate adaptation funds in Senegal and Mali, and 
devolution of planning powers to lower levels of governance in Kenya [10]. Kenya's Ending Drought Emergencies (EDE) framework aims to integrate multi-sectoral planning around the drivers of vulnerability in dry lands, which include conflict, climate change and demographic change [11].

Within the African region, the Horn countries are among the most vulnerable but least prepared for adverse global environmental change in the world. Among the Horn countries, Ethiopia is one of the most poverty stricken, ecologically fragile countries whose growing population and feeble economy are heavily impacted by climatic events [12]. Pastoral and agro-pastoral livelihood systems in the lowlands of the country are among the most vulnerable to the impacts of climate change and variability [13]. Over the past several decades, their livelihood systems were affected by repeated droughts, famine and epidemics that relate to the changing climatic condition. As a result, the losses of productive assets and increasing household food insecurity have become defining features of lowland poverty in Ethiopia [14-16].

Nutrition related health problems are among the Ethiopian government's priorities, especially towards the attainment of the Sustainable Development Goal 2 (SDG-2) to end hunger, food insecurity, and all forms of malnutrition [17]. Ethiopia costs about $16.5 \%$ of its annual Gross Domestic Product (GDP) for malnutrition [18]. The country has recently shown significant improvements in nutritional indicators nationally; however, the progress in the pastoral/agro-pastoral community is below the national figures $[19,20]$.

The Somali Regional State is one of the regions in Ethiopia affected by malnutrition, where almost all of the rural dwellers are pastoral/agro-pastoral communities. Child wasting (23\%) and anemia (87\%), and maternal anemia (59.5\%) are higher in the region than the national figures. Besides, minimum dietary diversity (3.8\%) among children aged 6-23 months is below the national level [21].

One of the reasons for these low achievements could be because of poor food choice decisions, which remains poorly understood. Furthermore, food choices are rapidly evolving in response to recent changes to pastoral/agro-pastoral community livelihoods and cultural norms in the face of climate change, urbanization, and other trends. Therefore, the aim of this study was to explore the drivers of the food choices among pastoral/agro-pastoral community in Somali Regional State of Eastern Ethiopia to provide information that is context-specific to allow for appropriate interventions.

\section{Materials and Methods}

2.1. Study Setting and Sampling. A qualitative study was conducted in four districts of Somali Regional State; namely Awbare, Kebribeyah, Shinile, and Erer districts. The Somali Regional State is the easternmost of the nine regions of Ethiopia. The region borders with Ethiopian regions of Oromia, Afar and Dire Dawa to the west, Djibouti to the north, and Somalia to the north, east and south.

The study included 16 FGDs and 6 KIIs. The study participants for the FGDs were selected separately for female and male groups. Accordingly, eight of the FGDs were male groups and the remaining eight FGDs were female groups. The participants in the FGDs were from the community, including clan and religious leaders. The age of the participants ranges from 26 to 58 years and the number of participants per FGD was 6-12 individuals resulting in 121 respondents. The participants for the KIIs were three nutrition experts who were working as district nutrition focal persons, one agricultural expert who was working in district agricultural office and two merchants who had food mini-markets in the study area.

The selection of all participants was based on their role in nutrition related activities. For the FGDs, individuals who were involved in food procurement, preparation and serving were mainly considered. For the KIIs, nutrition and agricultural experts were selected since they are government bodies, most concerned with the nutrition issues of the community. Moreover, food merchants, who sell food items in the study area, were selected as additional key informants to the experts as they can provide data regarding food choices of the community from the market.

2.2. Data Collection. The study used FGD and KII guides to collect the data. The data collection guides used for the FGDs and KIIs were generally similar in content. The differences were in data collection approach; the FGDs were conducted in discussion forms, whereas the KIIs were individual based interviews. Ten data collectors who had a diploma with previous qualitative data collection experience conducted the data collection. The data collectors were young native Somali language speakers and most of them were from the community. The data collection team for the FDGs had a female and a male interviewer, and collected the data from the female and male groups separately until the saturation of ideas in at least two consecutive FGDs. The KII sessions were conducted from nutrition and agricultural experts, and food merchants. The experts were males and they were interviewed by male interviewers. The merchant interviewees were females and female interviewers interviewed them. The reason why we assigned gender specific interviewers was to make participants free in expressing their ideas and experiences. In addition, gender specific data collections are effective in probing and getting detailed data in these communities, as there are gender norms. However, the study might have been suffered from age and gender related biases. The data collected from all the aforementioned sources were audio-recorded with a tape recorder.

To control the quality of the data, the data collectors were trained for two days on the data collection tool and the data collection procedure to have a common understanding. In addition, the principal investigators (researchers) closely supervised the data collection process.

2.3. Data Processing and Analysis. The collected data were first transcribed in the native language (Somali) and then translated to English by two native Somali language speakers who had Master's degree in Public Health with previous data transcription and translation experience. To minimize transcription and translation inconsistencies, a third individual with similar background and level of education compared the transcribed and translated data to the audio-recorded 
data. Then, the data were cleaned for errors and checked for completeness.

The cleaned data, both the FGDs and KIIs, were formatted, coded and sorted by the two principal investigators/researchers. The codes were sorted line-by-line and organized into categories. Repeated meetings were conducted to resolve the inter-coder discrepancies by comparing and discussing all the codes and categories line-by-line. Content analysis was used to drive/draw the emerging key themes and sub-themes from the codes and categories. Accordingly, two main themes emerged from the codes and categories; namely feeding habits and drivers of food choice. Under the drivers of food choice, nine sub-themes were identified.

2.4. Ethics Approval and Consent to Participate. Before starting the fieldwork, official letter was obtained from the PRIME Project of Haramaya University and submitted to the Somali Regional State Health Bureau. Then, ethical clearance was secured from the Somali Regional State Health Bureau Research Ethical Review Committee. Moreover, official letters were written from the regional health bureau to the districts. Informed consent was obtained from each participant after explaining the purpose and benefits of the study. Confidentiality of the study participants' information was also ensured.

\section{Results}

3.1. Feeding Habits. Most of the FGD respondents reported that they want to consume a wide range of food items, including vegetables and fruits. Nevertheless, porridge ("Shurow") and "Garaw" were found to be the commonest food items consumed on a daily basis. "Shurow" is porridge made from corn or wheat flour, and is sometimes mixed with milk or butter. "Garaw" is boiled bean, wheat or sorghum that is mixed with oil or sugar. Sometimes, some of them consume foods like rice, pasta, macaroni, Somali Injera ("Lohoh"), milk, meat and foods made from fava bean such as "Ful". However, the habit of consuming vegetables and fruits is not usual; rather it is seasonal.

One focal nutrition person noted, "They sometimes consume fruits and vegetables, but it is seasonal and it is not simple to get these foods because these communities are not farmers."

Concerning the meal frequency, these communities want to have at least three times a day to get the necessary nutrients. Additionally, they consider food items as nutritious/healthy if their meals include "Shurow" (porridge), rice, pasta, tuna, fruits, and vegetables. Moreover, locally produced food items are considered nutritious and healthy. They have also pointed out that proper hand washing before, during and after food preparation/serving, cleaning the cooking or serving materials and proper handling/preservation of foods should be considered as part of healthy feeding. However, as they reported, they do not fulfill the above-mentioned conditions.

\subsection{Drivers of Food Choices}

3.2.1. Drought. One of the major barriers to consuming nutritious/healthful foods reported by most of the respondents was drought, which results in a shortage of water and low production of local food items. It also causes the death of their livestock that leaves them with no domestic animals, and they were facing difficulty even in getting drinking water. They wait for the short period of rainy season. The production of food items during this season is also not productive because of the traditional way of farming.

A 44-year-old female FGD respondent expressed, "Our farmlands are dry and our domestic animals are dying because of drought. Currently, most of us have no livestock, and we are suffering from shortage of water even for drinking". In addition, a 50-year-old male FGD respondent said, "If we get access to water, we will be able to produce different varieties offoods and breed livestock. This, in turn, will improve our consumption of nutritious foods, and our income. Four years back, we were consuming different kinds of vegetables, fruits and other animal products because there was access to water".

3.2.2. Income. The respondents reported that they could not afford nutritious foods from markets because they do not have adequate income. In addition, they noted that they could not afford the seeds, and the farming materials to cultivate their land during the limited rainy season.

A 56-year-old male FGD respondent said, "Currently, we have no chance to choose food items due to inadequate income; we are simply eating what we get for survival without choosing the type of food". Likewise, a 36-year-old female FGD respondent reported, "There are many kinds offood items that are difficult for us to add to our daily meals such as meat, milk, butter, fruits, and vegetables. This is due to poor income and saving habit of our community."

3.2.3. Cost of Nutritious/Healthful Foods. The other challenge to consuming nutritious/healthy foods was the high cost of these food items.

One food merchant reported, "The price of vegetables and fruits is expensive due to the transportation cost, and these people do not buy these food items because they cannot afford; they always look for what is economical."

3.2.4. Availability of Nutritious/Healthful Foods. Geographical accessibility to the nutritious foods was also one of the driving factors to consuming these foods. The communities may sometimes have the power to afford some of the nutritious foods, but the foods are not usually available. This is due to poor infrastructures such as inaccessibility to roads, which prevents them from selling their animals in large markets and import nutritious food items.

A 34-year-old male FGD respondent reported; "one of our biggest challenges to consuming nutritious foods is physical inaccessibility". Similarly, one food merchant expressed, "If I want to bring food items like vegetables and fruits, I have to go far markets because they are not available or produced locally". Moreover, one nutrition focal person noted, "the absences of food industries or factories nearby the community prevent them not to get more nutritious food products."

3.2.5. Market Access. The other factor was markets were inaccessible to supply their products and import nutritious/ 
healthy foods. Agro-pastoralists produce limited varieties of foodstuffs like cereal crops, milk and meat, especially during the rainy season. The reason why they produce only these food groups is that they get nearby markets to sell these food items, which reduces the transportation cost. The study participants also responded that they tried to produce fruits and vegetables like watermelon, but they did not get nearby markets for these foodstuffs.

One agriculture focal person said: "The agro-pastoralists are producing limited food stuffs like wheat, maize, sorghum, milk and meat because there is market access to these food items. But there is limited market access for vegetables and fruits."

3.2.6. Quality of Foods. Some of the study participants choose the locally produced foods over imported ones because they consider them as organic, fresh, safe, and good sources of nutrients.

A 27-year-old female FGD respondent said; "if available, we prefer food items that we get from our farmlands because they are fresh, organic, and safe. Additionally, they are rich in proteins and vitamins."

3.2.7. Familiarity with New Foods. This was also another problem to consuming nutritious foods. The communities are not easily familiar with new and nutritious foods.

One nutrition focal person indicated, "We educate them to diversify their meals, including for their children. There are some improvements, but there is still a problem in utilization/adaptation of new food items, especially plant products due to unfamiliarity and poor feeding habits of those food items."

3.2.8. Knowledge of Nutritious/Healthful Foods. The participants responded that they do not usually consume nutritious/healthful foods because they have poor knowledge on the production, preparation and consumption of the nutritious foods. They added that they could improve their food choices if they get nutrition education and limited technical assistance/advices from agriculture and nutrition experts.

A 32-year-old female FGD respondent reported, "We are getting difficulty in making nutritious/healthy food selection because we have low awareness on how to produce, prepare and consume these foods". In addition, one agriculture focal person said, "There is shortage of qualified agricultural experts who can advise these communities on how to select the nutritious food items suitable for their farmlands and therefore, they are not producing nutritious foods such as fruits and vegetables."

3.2.9. Poor Health Conditions. The food choice decision was also found to be affected by the health condition of individuals in the community. This, in turn, can hinder utilization of nutritious/healthy foods.

One food merchant expressed, "Individuals having blood pressure eat foods without salt and butter; and those with diabetes mellitus eat foods without sugar."

\section{Discussion}

The study showed that the communities of the study area have the desire to produce and consume varieties of food items. However, they usually consume porridge ("Shurow") and/or "Garaw." Sometimes, they consume additional foods like rice, pasta, macaroni, Somali Injera ("Lohoh"), milk, meat and foods made from fava bean. However, the habit of consuming vegetables and fruits is seasonal. This indicates that their feeding habit is monotonous. Most of them consider feeding habit healthy if the meal frequency is at least three times a day, and if their meal includes "Shurow" (porridge), rice, pasta, tuna, fruits, and vegetables complemented with proper cooking, serving and handling of foods. However, they do not fulfill the above-mentioned conditions and they do not practice healthy feeding habit.

The major and deeply rooted barrier to consuming nutritious/healthful foods was drought. The occurrence of repeated drought in these communities is because they are one of the most climate change vulnerable groups on the planet [22]. Increased climate variability could decrease herd sizes because of increased mortality and poorer reproductive performance of the animals. This decrease in animal numbers would affect food security, and compromise the consumption of nutritious/ healthy diet [23]. In the arid and semi-arid regions of Kenya, for example, the loss of animals and subsequent losses in milk and meat production, because of increased drought frequency, could amount to more than US $\$ 630$ million by 2030 [24]. While traditional pastoral systems have inherent adaptive capacity, their ability to cope with drought and climatic shocks is challenged by continued environmental, political and socio-economic marginalization such as insecurity, lack of credit and public services, lack of human capital, limited technical knowledge, inadequate infrastructure, and limited access to markets [25].

The present study showed that income was found to be a powerful factor in making food choice decisions. Most of these communities cannot afford nutritious foods from markets because they do not have adequate income. They cannot even afford the seeds, and the farming materials to cultivate their land during the rainy season.

The other challenge of these communities to consuming nutritious/healthy diet was the high cost of these food items. Since there is low local food production secondary to climate change and variability, most of the food items are imported from other areas. This makes the cost of nutritious/healthy foods high. Climate extremes and disease shocks can lead to high price volatility and high transaction costs, and preventing participation in markets [26]. Structural inefficiencies in livestock markets including long distances to market, inconvenient timing and location of sales, high transport costs, high taxation, and insecurity play important role in the cost of food items [27].

Geographical accessibility/availability of the nutritious foods was also an important driving factor to consuming these foods. Some of the communities have the power to afford nutritious foods, but the foods are not usually available. This is due to poor infrastructures such as inaccessibility to roads to import the nutritious food items. Similarly, these 
communities were suffering from market inaccessibility to supply their products and import nutritious/healthy foods. They can produce limited varieties of foodstuffs during the rainy season, but they do not have adequate market access.

The study result also indicated that unfamiliarity to foods, especially the new and imported food items, was another factor that affects the consumption of nutritious foods. Most of these communities consider locally produced foods as more organic, safe, and good sources of nutrients. All these result in fear of the consumption of the imported new foods (food neophobia).

Knowledge of the production, preparation and consumption of the nutritious foods has also been identified as one of the drivers of food choice in the community. The poor awareness and knowledge of this community on nutrition could be due to low educational level, poor nutrition education and limited technical assistance/advices from experts. Even though the main factors in food choice decisions were drought, cost and availability of foods, nutrition knowledge is an important factor in diversifying and balancing the available food. Not all of them are poor; there are some pastoralists/agro-pastoralists with adequate access to food. However, their food selection/ preference is poor; this could be due to their low awareness and knowledge of nutrition specifically food choice.

According to the study, health status of individuals in the communities was found to influence the food choice decisions, and hinders to utilizing nutritious/healthy foods. This can be explained as those with different health conditions, such as diabetes and hypertension, are forced to modify their feeding habit; and they may miss some of the important nutrients. However, these noncommunicable diseases are not common in such kinds of communities and this is not a community level factor/driver. This is simply to mean that there are some individuals suffering from health conditions that affect their food choices.

To overcome the major factors that influence the food choice decisions, these communities should be encouraged to respond to drought by diversifying livelihood options such as cultivation, wage or salaried labor, trade, and business [28-31]. Supplementing pastoral incomes with farm or off-farm income [32], diversifying herd composition [33], supplementation of fodder, development of water sources (ground and rain water harvesting), saving/credit schemes, early warning systems, new market opportunities, education and cash transfers [23] are also important coping strategies to climate change and drought. Furthermore, insurance services, including transportation insurance and index-based livestock insurance (which has been piloted in Mongolia [34] and Kenya [35]), can reduce the risk of loans.

\section{Conclusions}

The feeding habit of the community was poor and monotonous that they were not practicing healthy food choices and feeding habit. The commonest influences/drivers of their food choices included drought, income, cost of nutritious/healthful foods, availability of nutritious/healthful foods, market access, quality of foods, familiarity with new foods, knowledge on nutritious/healthful foods, and health conditions of individuals.

Therefore, the government, in collaboration with other partners, should give concentrations on the utilization of underground water as alternative source to strengthen irrigation activities and improve production of food items locally. Additionally, the government has to encourage them to be settled and produce different food items by presenting seeds and other farming materials either as subsidies or in discounts. Improving infrastructures and establishing local food complexes (factories) are also important actions to make foods available in the area. The other option for improving food choice is counseling/advising the community by nutrition professionals regularly, on how to prepare diverse diet economically with the available food items in line with their culture of feeding. Repeated demonstrations on food preparation, including new food items, have to be conducted to the communities to improve diet diversification with the available food. This can also improve the familiarity of new food items.

\section{Abbreviations \\ FGD: $\quad$ Focused group discussion \\ KII: $\quad$ Key informant interview \\ PRIME: Pastoralist areas resilience improvement through market expansion.}

\section{Data Availability}

The datasets used and/or analyzed during the current study are available from the corresponding author upon request.

\section{Conflicts of Interest}

The authors declare that there are no conflicts of interest regarding the publication of this paper.

\section{Acknowledgments}

The authors would like to express their gratitude to the Somali Regional Health Bureau, District Health and Agricultural Offices of the study area, data collectors, study participants, questionnaire translators, and data transcribers and translators for their cooperation. Pastoralist Areas Resilience Improvement through Market Expansion (PRIME) Project of Haramaya University sponsored the study.

\section{References}

[1] UNICEF WHO World Bank, "Levels and trends in child malnutrition: joint report on child malnutrition," 2017, https:// www.who.int/nutgrowthdb/jme_brochoure2017.pdf.

[2] WHO, "Final report of the commission on ending childhood obesity," 2016, http://www.who.int/dietphysicalactivity/ childhood/en/. 
[3] FAO (Food and Agricultural Organization), "Pastoralism in Africa's drylands,” Rome52 pages, 2018, Licence: CC BY-NCSA 3.0 IGO.

[4] Feed the Future, “The U.S. Government's Global Hunger and Food Security Initiative. Ethiopia pastoralist areas resilience improvement and market expansion survey," (PRIME) Project Impact Evaluation Report of the Interim Monitoring 2014-2015, 2015.

[5] E. Adugna, "Is settling pastoralists a viable livelihood strategy? Implication for policy dialogue," Scholarly Journal of Agricultural Science, vol. 2, no. 5, pp. 94-102, 2012.

[6] S. Hallegatte, "Strategies to adapt to an uncertain climate change," Global Environmental Change, vol. 19, no. 2, pp. 240-247, 2009.

[7] S. J. Lloyd, R. S. Kovats, and Z. Chalabi, "Climate change, crop yields, and undernutrition: development of a model to quantify the impact of climate scenarios on child undernutrition," Environmental Health Perspectives, vol. 119, no. 12, pp. 1817-1823, 2011.

[8] P. J. Ericksen, "Conceptualizing food systems for global environmental change research," Global Environmental Change, vol. 18, no. 1, pp. 234-245, 2008.

[9] P. K. Thornton, P. J. Ericksen, M. Herrero, and A. J. Challinor, "Climate variability and vulnerability to climate change: a review," Global Change Biology, vol. 20, no. 11, pp. 3313-3328, 2014.

[10] C. Hesse, S. Anderson, L. Cotula, J. Skinner, and C. Toulmin, "Managing the boom and bust: supporting climate resilient livelihoods in the Sahel," in International Institute for Environment and Development (IIED), London, 2013, IIED Issue Paper, http://pubs.iied.org/pdfs/11503IIED.pdf.

[11] E. Carabine, M. Jouanjean, and J. Tsui, "Kenya ending drought emergencies policy review: scenarios for building resilience in the ASALs. In Technical Report Series No. 2: Strengthening the evidence base for resilience in the Horn of Africa," International Livestock Research Institute, 2015, https://www.odi.org/ publications/9079-kenya-endingdrought-emergencies-policyreview-scenarios-buildingresilience-asal.

[12] A. Aklilu and A. Alebachew, Assessment of Climate ChangeInduced Hazards, Impacts and Responses in the Southern Lowlands of Ethiopia, Forum for Social Studies (FSS), Addis Ababa, 2008.

[13] NMA (National Meteorological Agency), Climate Change National Adaptation Program of Action (NAPA) of Ethiopia, NMA, Addis Ababa, 2007.

[14] S. Sandford and H. Yohannes, Emergency Response Interventions in Pastoral Areas of Ethiopia: Report of the Pastoral Appraisal Team, Department forInternational Development (DFID), UK, 2000.

[15] Y. Beruk, Food Security Situation in the Pastoral Areas of Ethiopia, Oxfam GB, Addis Ababa, 2003.

[16] S. Pantuliano and M. Wekesa, "Improving drought response in pastoral areas of Ethiopia Somali and Afar Regions and Borena Zone of Oromiya Region. Prepared for the CORE group (CARE, FAO, Save the Children UK and Save the Children US)," Overseas Development Institute, London, 2008.

[17] L. C. Smith and L. Haddad, "Reducing Child Undernutrition: Past Drivers and Priorities for the Post-MDG Era," World Development., vol. 68, pp. 180-204, 2015.

[18] "Cost of hunger ( $\mathrm{COH})$. implications for the growth and transformation of Ethiopia: COHA summary report," pp. 1-24, 2012, https://reliefweb.int/sites/reliefweb.int/files/resources/
FINAL \%20Ethiopia \%20-\%20COHA \%20Summary $\% 20$ Report\%20June\%2028.pdf.

[19] UNICEF EU, "Situation Analysis of the Nutrition Sector in Ethiopia," 2015.

[20] “SUN Movement Secretariat," 2015, Progress report.

[21] Central Statistical Agency (CSA), "Ethiopian Demographic and Health Survey," pp. 202-215, 2016.

[22] P. Thornton, J. Van De Steeg, A. Notenbaert, and M. Herrero, "The impacts of climate change on livestock and livestock systems in developing countries: a review of what we know and what we need to know," Agricultural Systems, vol. 101, no. 3, pp. 113-127, 2009.

[23] M. Herrero, J. Addison, C. Bedelian et al., "Climate change and pastoralism: impacts, consequences and adaptation," OIE Revue Scientifique et Technique, vol. 35, no. 2, pp. 417-433, 2016.

[24] M. Herrero, C. Ringler, J. van de Steeg et al., "Climate variability and climate change and their impacts on the Kenya's agricultural sector," International Livestock Research Institute (ILRI), Nairobi, Kenya, 2010, ILRI report to the World Bank for the project Adaptation to climate change of smallholder agriculture in Kenya, https://cgspace.cgiar.org/bitstream/ handle/10568/3840/climateVariability.pdf.

[25] J. Ø. Nielsen and A. Reenberg, "Cultural barriers to climate change adaptation: a case study from northern Burkina Faso," Global Environmental Change, vol. 20, no. 1, pp. 142-152, 2010.

[26] C. B. Barrett, "Livestock pricing and markets performance Research Brief 01-05-PARIMA," Global Livestock Collaborative Support Program, University of California, Davis, 2001, http://barrett.dyson.cornell.edu/files/papers/150804_Barrett_ LivestockPricing.pdf.

[27] Kenya Markets Trust (KMT) Agency for Technical Cooperation and Development (ACTED), "Can markets work for the Turkana pastoralists? An analysis of livestock market systems in Turkana Country," KMT, Nairobi, 2014.

[28] F. Opiyo, O. Wasonga, M. Nyangito, J. Schilling, and R. Munang, "Drought adaptation and coping strategies among the Turkana pastoralists of northern Kenya," International Journal of Disaster Risk Science, vol. 6, no. 3, pp. 295-309, 2015.

[29] P. D. Little, K. Smith, B. A. Cellarius, D. L. Coppock, and C.Barrett, "Avoiding disaster: diversification and riskmanagement among East African herders," Development and Change, vol. 32, no. 3, pp. 401-433, 2001

[30] P. Kristjanson, M. Radeny, D. Nkedianye et al., "Valuing alternative land-use options in the Kitengela wildlife dispersal area of Kenya. A joint ILRI (International Livestock Research Institute)/ACC (African Conservation Centre) Report," ILRI, Nairobi, 2002, ILRI Assessment Series 10, https://cgspace.cgiar. org/bitstream/handle/10568/506/KitengelaImpactAssessment. pdf? sequence $=1$.

[31] K. Homewood, P. Kristjanson, and P. C. Trench, Staying Maasai? Livelihoods, Conservation and Development in East African Rangelands, Springer, New Yorkp. 408, 2009.

[32] A. Catley, J. Lind, and I. Scoones, "Development at the margins: pastoralism in the Horn of Africa," In Pastoralism and development in Africa: dynamic change at the margins, Routledge, Oxfordpp. 1-26, 2013.

[33] J. Ogutu, N. Owen-Smith, H. P. Piepho, and M. Said, “Continuing wildlife population declines and range contraction in the Mara region of Kenya during 1977-2009," Journal of Zoology, vol. 285, no. 2, pp. 99-109, 2011. 
[34] O. Mahul and J. R. Skees, "Managing agricultural risk at the country level: the case of index-based livestock insurance in Mongolia," World Bank, Washington, DC, 2007, Policy Research Working Paper 4325.

[35] S. Chantarat, A. G. Mude, C. B. Barrett, and M. R. Carter, "Designing index-based livestock insurance for managing asset risk in northern Kenya," Journal of Risk and Insurance, vol. 80, no. 1, pp. 205-237, 2013. 


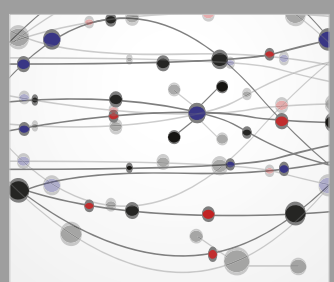

The Scientific World Journal
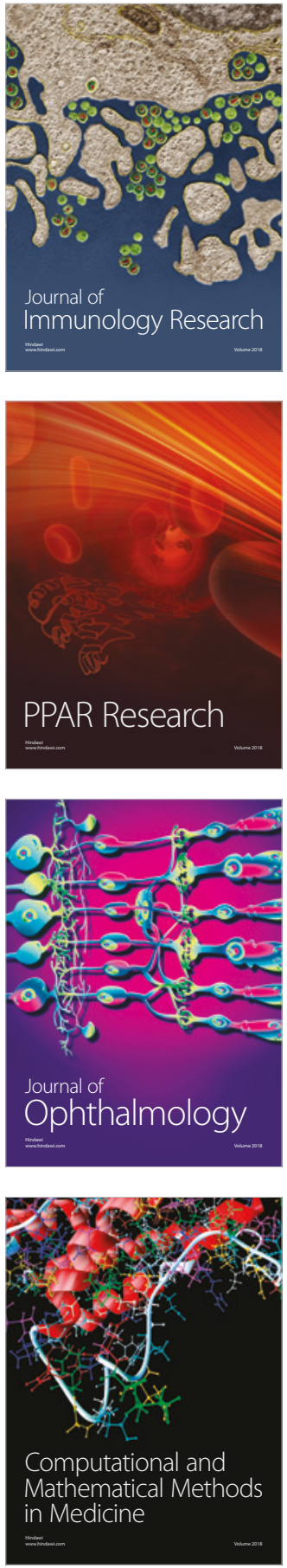

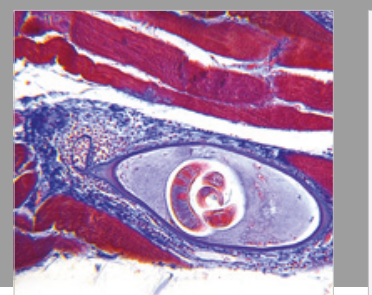

Gastroenterology Research and Practice

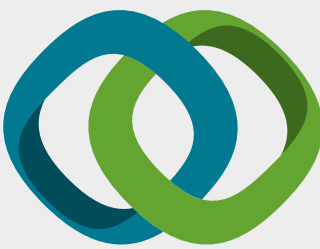

\section{Hindawi}

Submit your manuscripts at

www.hindawi.com
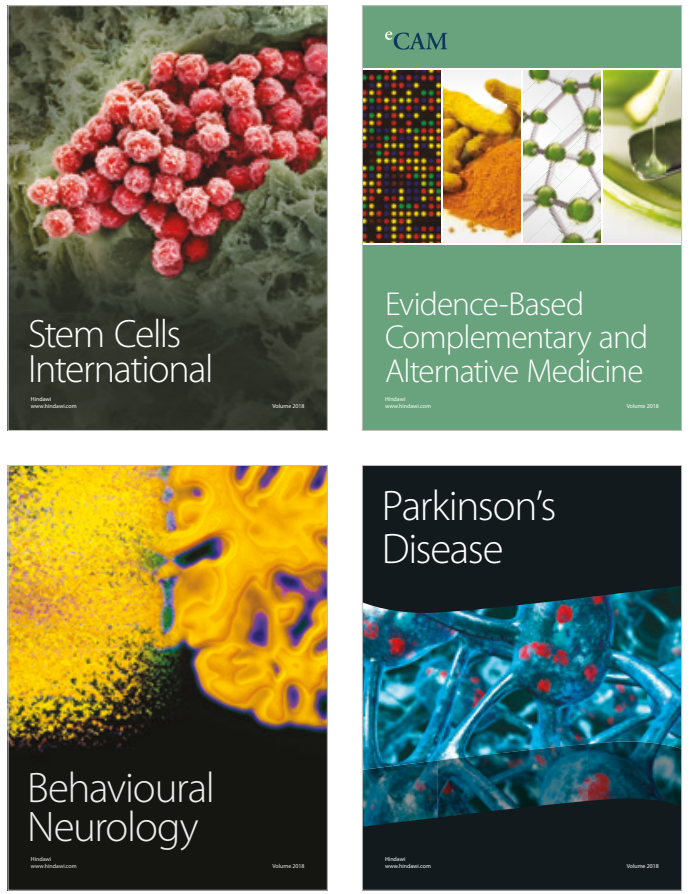

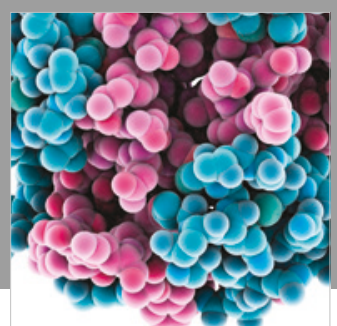

ournal of

Diabetes Research

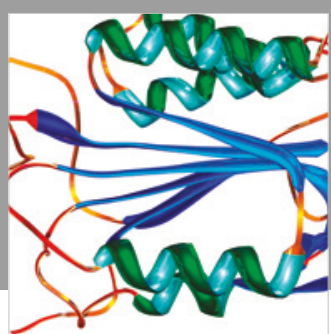

Disease Markers
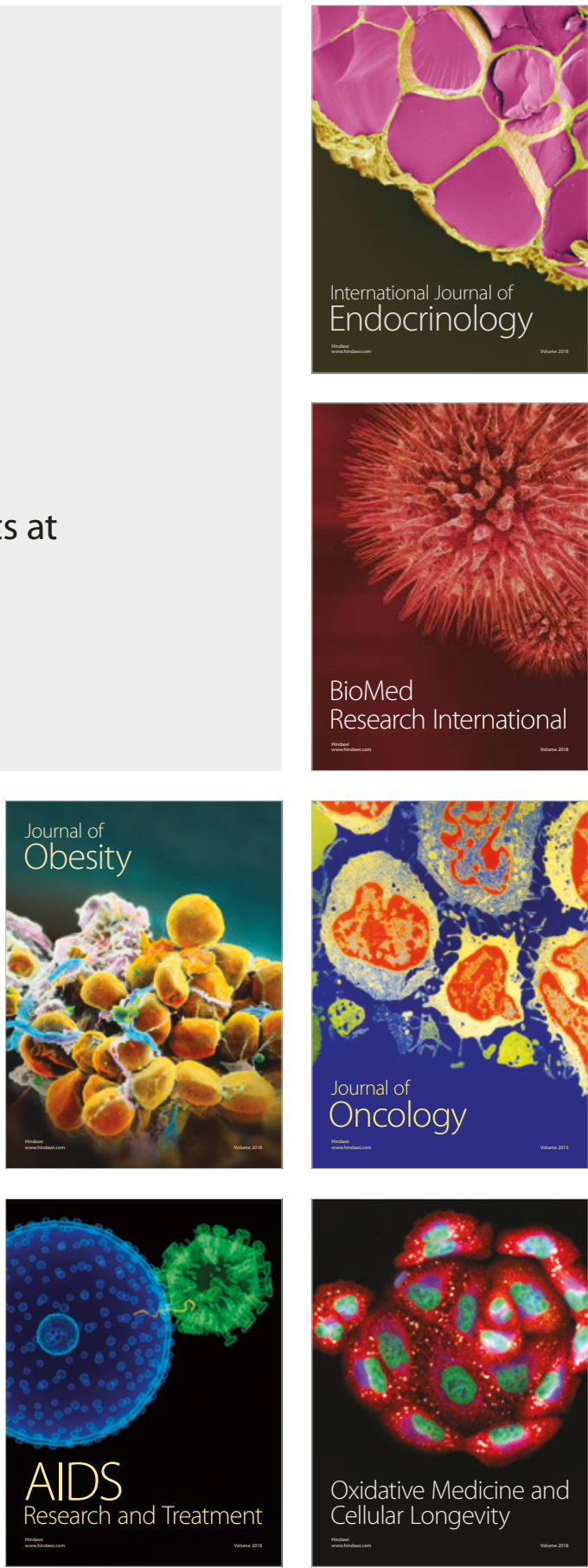